\title{
Instrumentation and monitoring of cave initiation at Telfer Mine
}

\author{
M. Di Giovinazzo Newcrest Mining Limited, Australia \\ U. Singh Newcrest Mining Limited, Australia
}

\begin{abstract}
The Telfer Gold Mine is a Newcrest Operation located in the northwest of Western Australia within the Paterson Province East of the Pilbara Craton. The modern operation consists of the Main Dome Open Pit and the Telfer Deeps Underground Mines. The underground sublevel caving mine commences approximately $850 \mathrm{~m}$ below surface and has a production rate of approximately 6 million tonnes per year. Undercutting commenced in 2006 and pre-existing excavations above the cave footprint were used for cave instrumentation and monitoring. Cave monitoring techniques employed were a combination of a 14 geophone microseismic array, eight deep-hole extensometers, one open borehole and visual observations of pre-existing excavations. A case study is presented on the combined response of the monitoring systems from the beginning of undercut development through to cave initiation and early propagation. This data set enabled interpretation of rock mass response to caving, identification of air gap, and correlation of these with variable draw rates. The monitoring and interpretations were used to manage risks associated with cave initiation and early propagation.
\end{abstract}

\section{Introduction}

Newcrest Mining Limited (NML) owns and operates Telfer underground and open pit mines located in the northwest of Western Australia. The history of mining at Telfer is extensive and since 2003 exploitation from underground has seen the development and mining of a sublevel cave (SLC) below the active Main Dome Open Pit and pre-existing stope excavations. The $42 \mathrm{Mt}$ underground reserve at $1.6 \mathrm{~g} / \mathrm{t} \mathrm{Au}, 0.35 \% \mathrm{Cu}$ containing $2.2 \mathrm{Moz} \mathrm{Au}$ and $140 \mathrm{kt} \mathrm{Cu}$ is extracted at a rate of 5.7 million tonnes per annum drawn from sublevels commencing at $850 \mathrm{~m}$ below the surface.

Caving mines industry wide have recognised the requirement for real-time and spatial monitoring of cave related ground deformation. Benchmarking the experience of other monitoring programs assisted the design and timing of installation of Telfer's seismic array, deep-hole extensometers and open hole. The availability of data from the monitoring systems installed greatly assisted the interpretation of the location of the cave extents and the rate of cave propagation.

This paper summarises the design rationale and timing of installation; as well as the data recording and application to the interpretation of Phase 1 cave progress, which was from initiation through to propagation of the cave to a height of approximately $200 \mathrm{~m}$.

\section{Geology and mineralisation}

Telfer is recognised as a world-class gold-copper mine and is located within the northeastern portion of the Paterson Province, a belt of metamorphosed Palaeoproterozoic to Neoproterozoic sedimentary and igneous rocks which is exposed along the eastern margin of the Pilbara Craton of Western Australia. Gold-copper mineralisation in concordant bedding parallel reefs overprinted by late-stage, granite-related, discordant veins, breccia zones, stockwork zones within the crestal region of openly folded bedded pelitic sediments of Main Dome. Known mineralisation extends vertically over approximately 1,500 $\mathrm{m}$ within the Telfer and Malu Formation stratigraphy.

The formation is further subdivided into the Upper, Middle, and Lower Malu Members (UMM, MMM, and LMM respectively) based on the distribution of massive sandstone and pelitic strata. Lithologies range from massive quartz sandstones to finely laminated carbonaceous siltstones and are host to a series of quartzpyrite reefs. The MMM is located immediately above the SLC. 
Monoclinal folding and associated thrust-faulting overprints the early Telfer Dome folding event. These fold and thrust structures are known to intersect the Main Dome in a north-south strike direction and are typically $1 \mathrm{~km}$ in strike length, and 50-200 m wide (local mine grid north is $44^{\circ}$ west of magnetic north and is referenced in this paper). The $\mathrm{I} 30$ Monocline is shown to strike at about $355^{\circ}$ structural studies also suggest that monoclinal development in the Telfer Deeps region was formed as a result of northwest over southeast crustal movement of the UMM strata over the MMM strata. The I30 and B30 Reefs (lower SLC) represent the primary upper and lower tectonic interfaces during formation of the I30.

The Graben Fault Zone (GFZ) is the largest structural feature in Main Dome. It is a subvertical, $90 \mathrm{~m}$ wide dextral fault system. The fault zone comprises an anastomosing array of faults and fracture zones, with orientations varying from north-south to northeast-southwest. The GFZ strikes across the extent of Main Dome and extends through to the Telfer Deeps with the lowest intersection at 1,100 m below surface. This zone does not intersect with the $4650 \mathrm{~m} \mathrm{RL}$ undercut footprint.

\section{Rock mass properties}

The geotechnical feasibility study of the Telfer Deeps was completed by SRK Consulting in 2002 (SRK, 2002). In general the rock mass quality above the undercut is controlled by lithology with the intact rock strength varying from $85 \mathrm{MPa}$ for Reefs to $200 \mathrm{MPa}$ for Sandstone. Discontinuity frequency varies relative to the Main Dome fold hinge position with subhorizontal and subvertical structural sets resulting in a well jointed rock mass. Further sub-domaining of available drillhole data was done based on structural geology assessments and rock quality between reef locations through the caving column (Figure 1). The structural history of the Telfer Dome has provided the blocky environment with up to five sets including two orthogonal and persistent families. Three sub-domains were identified structurally parallel and progressively east of the GFZ. The summary statistics are listed in Table 1 (Groocock, 2006; Maxlow, 2007).

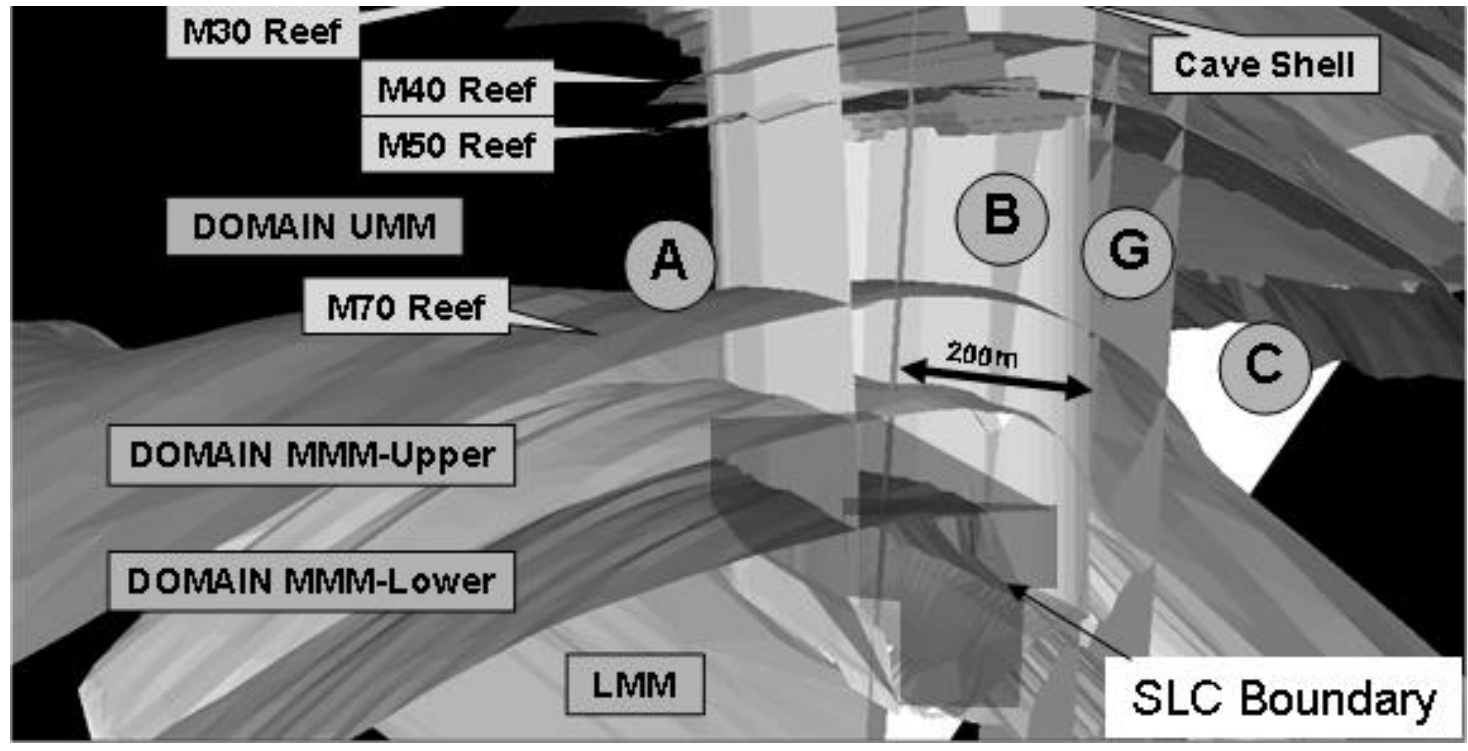

Figure 1 View looking NE of Telfer showing the Main Dome folding, geotechnical domains and the SLC boundaries (Maxlow, 2007)

\section{$4 \quad$ Mine design and extraction sequence}

SLC is a top down mining method which relies on the progressive blasting and extraction of ore in horizontal packages through the economically mineralised volume (Pfitzner, 2003). Underground capital development of the Telfer SLC commenced in 2003 to mine the mineralised MMM and LMM units. Prior to this only access and bulk sampling drives were mined.

A main decline is used to access each production level on the eastern side of the orebody. On each level, a perimeter drive is developed on the eastern side and slot drive on the western side of the orebody running north and south parallel to the monocline hinge line orientation crosscuts, with dimensions of $5 \mathrm{~m}$ wide and 
$4.7 \mathrm{~m}$ high, are spaced at $14 \mathrm{~m}$ centres leaving $9 \mathrm{~m}$ pillars. The slot drive is mined on the western side of the orebody and is developed to the north and south from a central crosscut.

The slot production from where the level is initiated is blasted north and south, away from the central cross cut along the slot drive. Crosscut production is retreated from west to east and commenced once the full slot height has advanced at least $20 \mathrm{~m}$ past cross cut to be initiated. The central crosscuts are retreated first followed by the crosscuts immediately to the north and south and the level is extracted in a stepped ' $\mathrm{V}$ ' shape. This sequence was adopted to attempt to shadow crosscut access to production from the major principal stress which is orientated with a $11-20^{\circ}$ dip in a $110-130^{\circ}$ direction.

The SLC was undercut on the $4650 \mathrm{~m}$ level ( $850 \mathrm{~m}$ below surface). The $4650 \mathrm{~m}$ undercut was drawn at $50 \%$ out of a $20 \mathrm{~m}$ high, $330 \mathrm{~m}$ long and $180 \mathrm{~m}$ wide volume. The subsequent production levels, 4625 and below, are each $25 \mathrm{~m}$ high and were stepped out to the north and south increasing the strike length of the foot print to $800 \mathrm{~m}$.

SLC production commenced in the southern third of the 4650 undercut level to utilise an existing raise bore vent rise and a ventilation access drive which provided additional relief for the slot. The $4640 \mathrm{~m}$ RL vent access drive was $40 \mathrm{~m}$ long and was situated between the 4650 and 4625 SLC levels on the west side of the foot print. As a result the 4625 commenced in this area early to extract the immediate crosscuts enabling a 'normal' production retreat thereafter. Initial undercut back fallout is likely to have occurred earlier due to a void of greater than $20 \mathrm{~m}$ height being created in this sub-footprint.

Table 1 Median $\mathrm{RMR}^{89}$ and average fracture frequency for the cave column above the SLC; refer to Figure 1 for domain locations

\begin{tabular}{llll}
\hline $\begin{array}{l}\text { Structural } \\
\text { Sub-domain }\end{array}$ & $\begin{array}{l}\text { Stratigraphical } \\
\text { Sub-domain }\end{array}$ & $\begin{array}{l}\text { Median } \\
\text { RMR }^{\text {99 }}\end{array}$ & $\begin{array}{l}\text { Average Fracture } \\
\text { Frequency (per m) }\end{array}$ \\
\hline A & MMM & 61 & 5.9 \\
A & LMM & 60 & 4.2 \\
B & MMM & 54 & 4.2 \\
B & LMM & 57 & 6.9 \\
G & MMM & 48 & 7.7 \\
G & LMM & 50 & 7.1 \\
\hline
\end{tabular}

\section{$5 \quad$ Monitoring systems}

A combination of microseismic sensor array, deep-hole extensometers were employed to track the rock mass response to undercut extraction. Pre-existing excavations vertically above the undercut footprint were available for drilling, installation of these systems and to provide a platform for visual inspection.

\subsection{Design rationale}

Ridgeway SLC and other caving operations were benchmarked for the design approach to monitoring systems. Newcrest's risk management approach of major hazard management plans (MHMP) were further developed from the Ridgeway experience. Trigger and response procedures specific to risk potential formulated a set of controls that needed to be established in order to understand quantitatively the risk of the SLC to both the underground and surface operations. Telfer's challenges with the SLC method included: low width to height ratio of undercut level relative to the cave column, air-blast risk due to the intersection of pre-existing excavations, and cave intersection into active open pit operations.

Monitoring performance requirements were:

- microseismic response was required prior to the initiation of the undercut extraction in order to establish a base set of data and to understand mining and other seismic influences relative to cave related seismic response 
- direct displacement measurement of cave front advance rate in real time and space

- prediction of air gap volume potential and location relative to open excavations intersecting the cave

- staging of monitoring systems to ensure at least two methods are operational and effective at any time through the cave front advance (Pfitzner, 2003).

\subsection{Microseismic system}

Integrated Seismic Systems International (ISSI) of South Africa supplied and installed the microseismic system which was commissioned in August 2005. Drilling of horizontal boreholes was by an in-the-holehammer percussion drill rig (ITH) to $15 \mathrm{~m}$. An array of $144.5 \mathrm{~Hz}$ triaxial geophones were grouted within the $90 \mathrm{~mm}$ diameter horizontal boreholes between 10-15 m depth. Geophones were linked by shielded twisted copper cable to communicate via analogue signal to Quake Seismometers (QS) which accommodate up to six channels each which is equivalent to two triaxial sensors. QS boxes all linked via copper wire transmitting digital signal to a run-time system hosted on a desktop computer with a Linux operating system.

The spacing of sensors ranged between $96 \mathrm{~m}$ and $320 \mathrm{~m}$ arranged around the working SLC levels and approximately $240 \mathrm{~m}$ above the undercut level (Figure 2). Velocity calibration of the system was done with two separate blasts centrally surveyed to the array using $1.5 \mathrm{~m}$ length Powergel cartridge explosives (approximately $5 \mathrm{~kg}$ explosive weight). Individual XYZ component orientations were iterated and $\mathrm{P}$ - and $\mathrm{S}$-wave velocities of $5,850 \mathrm{~m} / \mathrm{s}$ and $3,650 \mathrm{~m} / \mathrm{s}$ were back calculated respectively.

Theoretical analysis prior to collection of data reported the sensitivity of the microseismic system better than -1.5 Local Magnitude $\left(\mathrm{M}_{\mathrm{L}}\right)$ with location accuracy of approximately $10 \mathrm{~m}$ (Glazer, 2005). Background data was collected from August 2005 and a reliable dataset was recorded before extraction from the undercut commenced.

System functionality was above $90 \%$ for cave progression during Phase 1 . All sensors and cabling are still functional at the time of writing except for four that were consumed by cave progression (Sites 5, 8, 9 and 10). Access and cable lengths were a limitation of the system design; however, an upgrade with additional sensors and an improved long-term communications system was implemented to ensure that the seismic system continued to provide useful information once Phase 1 had been completed.

\subsection{Open hole dipping}

It was initially intended to have two open boreholes with no fixed instrumentation installed. These were to intersect the caving front to measure the location of the cave back, the air gap and the height of caved material in the cave. One was drilled parallel to an extensometer hole but the area from where it was collared was not accessible when the cave backs intersected the hole due to the closure of this area. However, prior to instrument installation, one other borehole was utilised for dipping measurement for a period of 12 days. This borehole was approximately at the centre of the early extraction dimensions of $140 \mathrm{~m}$ long, $75 \mathrm{~m}$ wide and $20 \mathrm{~m}$ high footprint (approximately 35\% of full undercut design). ITH drilling ended in intact rock at least $8 \mathrm{~m}$ above the $4675 \mathrm{~m}$ RL blasted back height. Early fallout from the undercut back intersected this borehole indicated by up-casting airflow. Table 2 is a summary of the dipping data recorded up until extensometer installation.

Telfer was only able to gain dipping data from one hole and therefore interpretation of cave back and air gap was not directly measured after November 2006. 

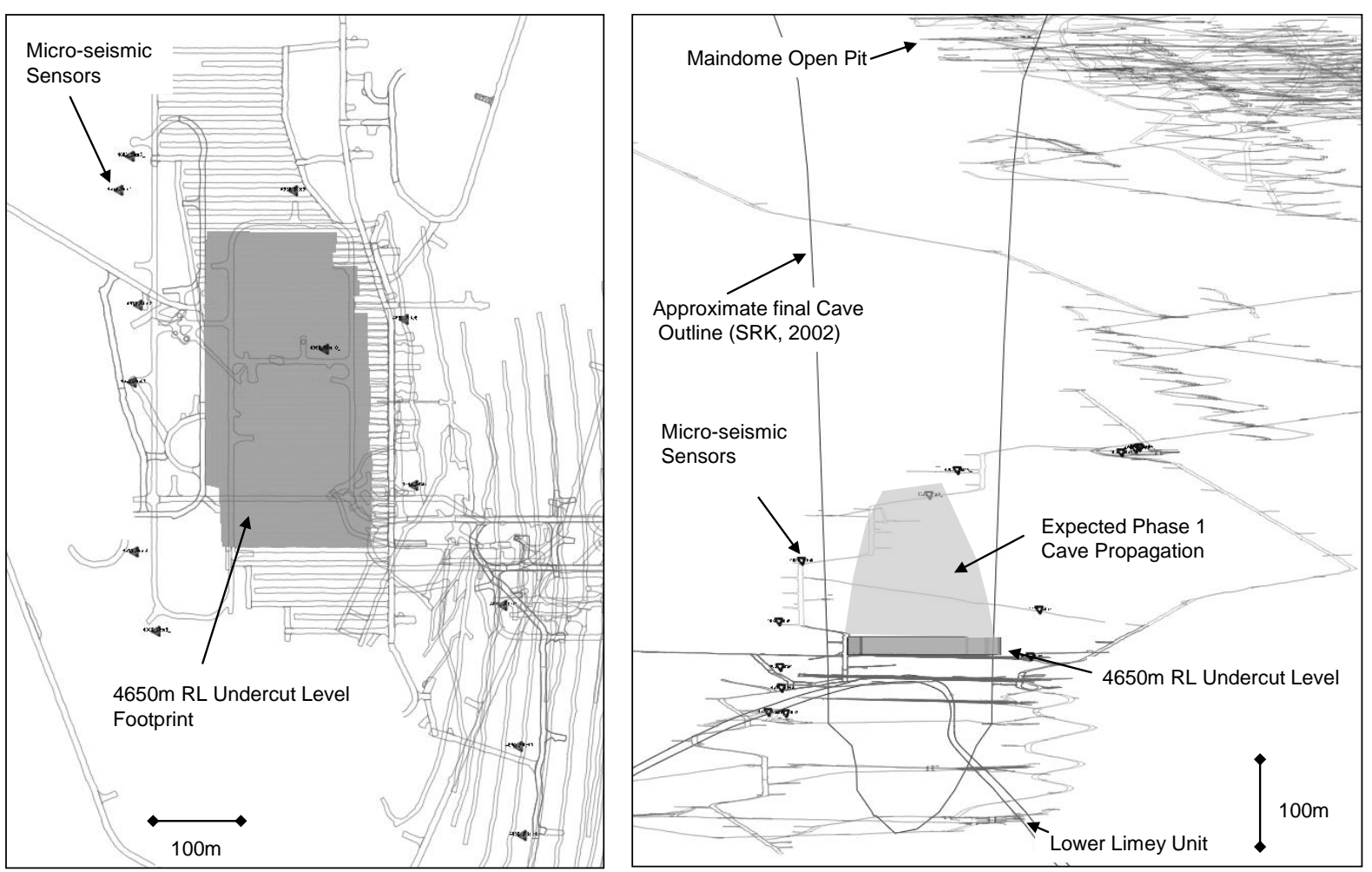

Figure 2 Phase 1 microseismic sensor array: a) plan view of array with $4650 \mathrm{~m} \mathrm{RL}$ design undercut footprint; b) section view looking towards the north of array in proximity to expected Phase 1 cave propagation relative to full cave column to intersect Main Dome Open Pit

Table 2 Open-hole dipping depth data from 4792 level location

\begin{tabular}{lllll}
\hline Date & Back $(\mathbf{m})$ & Muck $(\mathbf{m})$ & Air Gap $(\mathbf{m})$ & Comment \\
\hline $15 / 10 / 2006$ & 109 & - & - & Drill hole completed \\
$12 / 11 / 2006$ & 88 & 98 & 10 & - \\
$15 / 11 / 2006$ & 77 & 80 & 3 & - \\
$24 / 11 / 2006$ & 77 & 77 & 0 & Extensometer installation \\
\hline
\end{tabular}

\subsection{Deep-hole extensometers}

A series of eight deep-hole subsidence extensometers (DHSE) of variable length were installed from the existing excavations above the 4650 level by Geotechnical Systems of Australia. The anchors were set within $140 \mathrm{~mm}$ diameter drill holes which were bored with an ITH drill rig from 15 October 2006 to 19 November 2006. Installation and commissioning spanned a period from 23 November 2006 to 5 January 2007.

The decision to use DHSEs was made based on remote monitoring experience from Ridgeway and other caving operations (Pfitzner, 2003). The headframes were located in areas that were only accessible for a finite period and therefore the requirement was for frequent continuous logging of data over analogue signal linked by copper twisted pair cable up to $750 \mathrm{~m}$ distance. The details and benefits of the system are:

- anchors of spring stainless steel with tempered pointed tips configured in an inverted tripod shape

- each hole accommodated 11-17 anchors installed at a $10 \mathrm{~m}$ spacing and individually connected to spring loaded pulleys ('pots') in the headframe by high tension low yield stainless steel wire

- movement is measured using potentiometers with a sensitivity of $+/-1 \mathrm{~mm}$ 
- each anchor can measure up to 3,000 mm displacement

- anchors can function under shear and extensional conditions

- continuous readings were taken for each anchor at 10 minute intervals.

Eight instruments were installed in Phase 1. The existing decline from $4866 \mathrm{~m} \mathrm{RL}$ down to $4972 \mathrm{~m} \mathrm{RL}$ (Figure 3) were chosen as a suitable site to cover the undercut footprint, early monitoring of the full northsouth SLC strike extent, and to target the GFZ (Wienand, 2006). Full access for drilling, installation and maintenance was available for these locations for the early periods of cave initiation and propagation.

Displacement data logging was achieved by remotely locating a Campbell Scientific Logging unit at the $4886 \mathrm{~m}$ RL (Figure 3). This unit enabled cyclic data capture and storage from all eight headframes at 10 minute intervals. Communications via Ethernet linked to the local area network (LAN) which is established through the mine and is accessible from desktop computers in the surface office. Data was routinely uploaded from the logging unit and processed (Figure 4).

Considering the closure of access to the DHSE instruments, they proved to be reasonably reliable with four out of the eight functioning through to $3 \mathrm{~m}$ anchor displacement for most anchors. The other units were likely affected by moisture on electrical terminals or cable damage due to yielding rock mass in the decline area (Station 3 and 4; Figure 3).

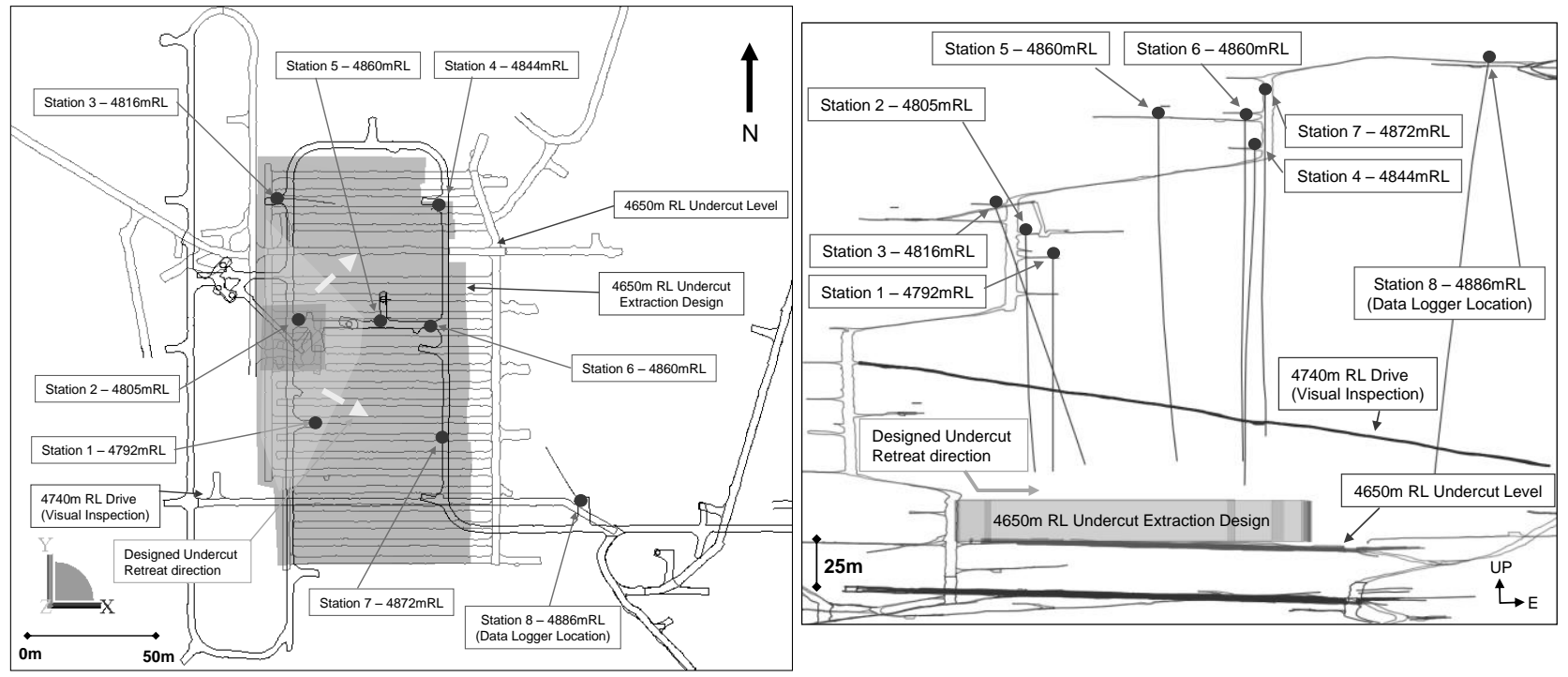

Figure 3 Extensometer installation and data logger sites above the SLC; plan view (left), and crosssection view looking north (right)

\subsection{Visual observations of excavations}

The configuration of existing excavations was fortunate for the early observations of deformation above the undercut foot print. Based on risk analysis, restricted access to the 4740 drive and decline system (Figure 3) allowed photography and crude measurements of vertical dilation of the subhorizontal discontinuities to be made. This was compared to the interpreted proximity of the caving which had been established using the seismic system. 
Cumulative Deformation - STATION 5 (4860m RL)

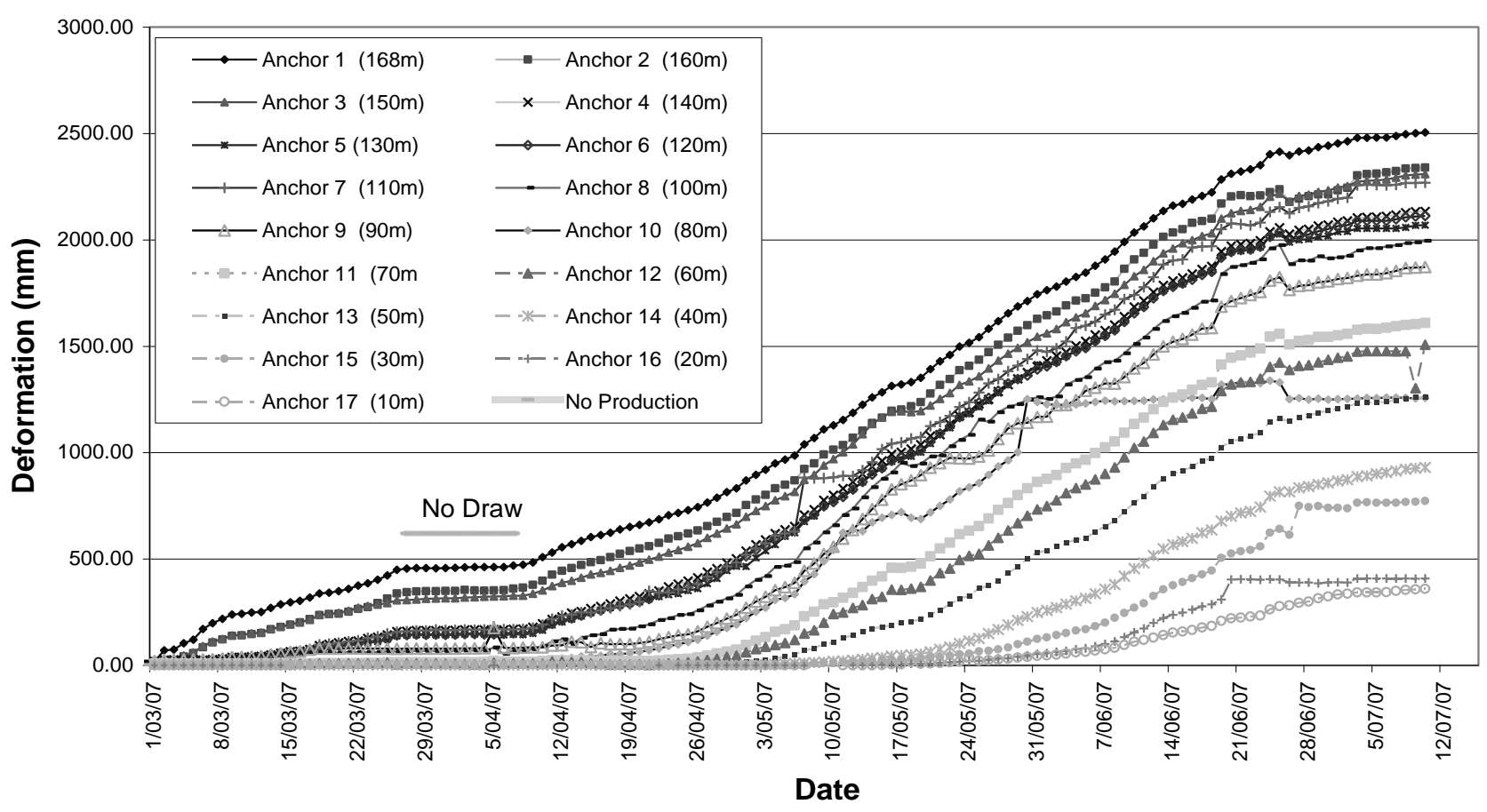

Figure 4 Example of DHSE data recorded from Station 5 displaying cumulative displacement of all anchors

\section{Application of monitoring data}

The combined application of monitoring data enabled the interpretation of cave initiation, caving front location and advance rate with reasonable confidence. Microseismic data was visualised spatially using JDI (ISSI, 2007). Event frequency and clustering began in June 2006. The intersection of the 4792 drill hole with cave back enabled cross referencing of the developing seismogenic zone and data from dipping the drill hole (Figure 5). This early fallout area, described in Section 5.3, had a hydraulic radius (HR) of approximately 25. The approximate HR range for transitional to caving is 25-35 based on Laubscher's 1994 Caveability Chart (Laubscher, 1994) (Figure 6). This was unlikely to be actual cave initiation but local instability of the undercut backs, that failed until the failure was choked off by material filling the void.
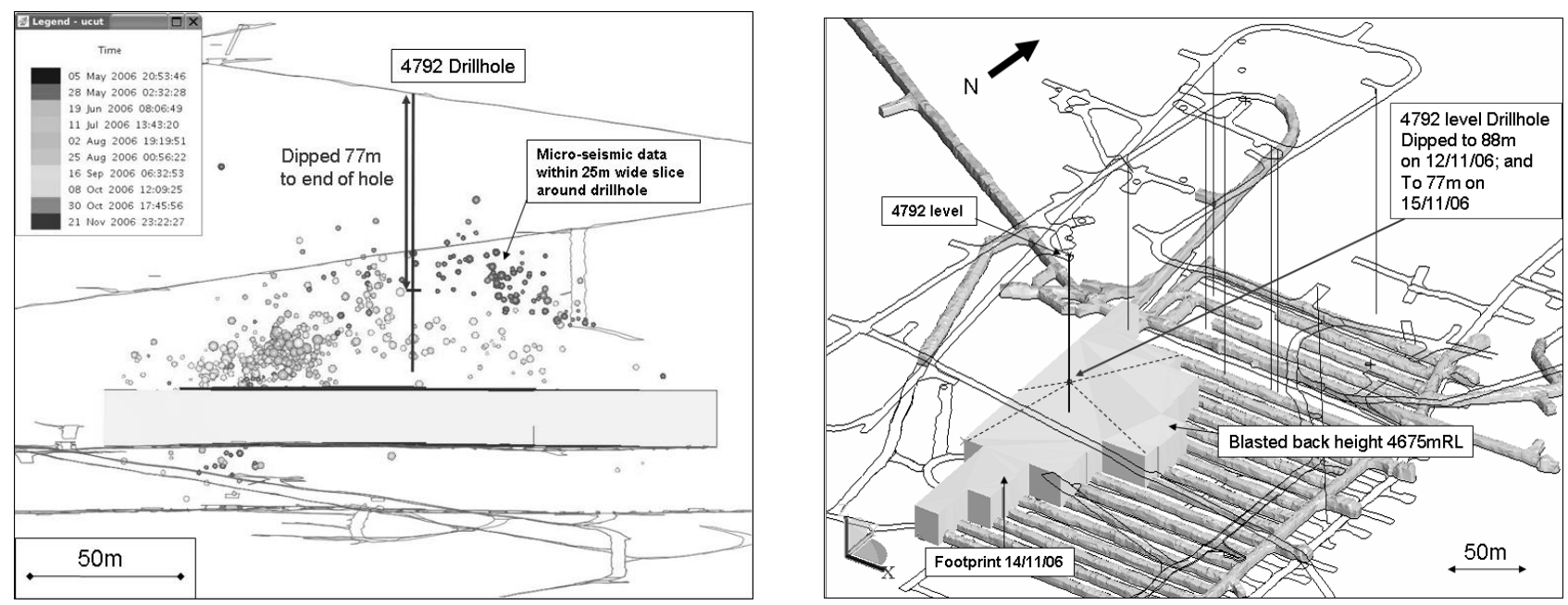

Figure 5 Left: view looking east of $4792 \mathrm{~m}$ RL open-hole and seismogenic zone at time of dipping (15 November 2006); right: oblique view looking northwest of early 4650 level extraction and drill hole dipping results 


\section{TELFER 4650 LEVEL HYDRAULIC RADIUS PROGRESS}

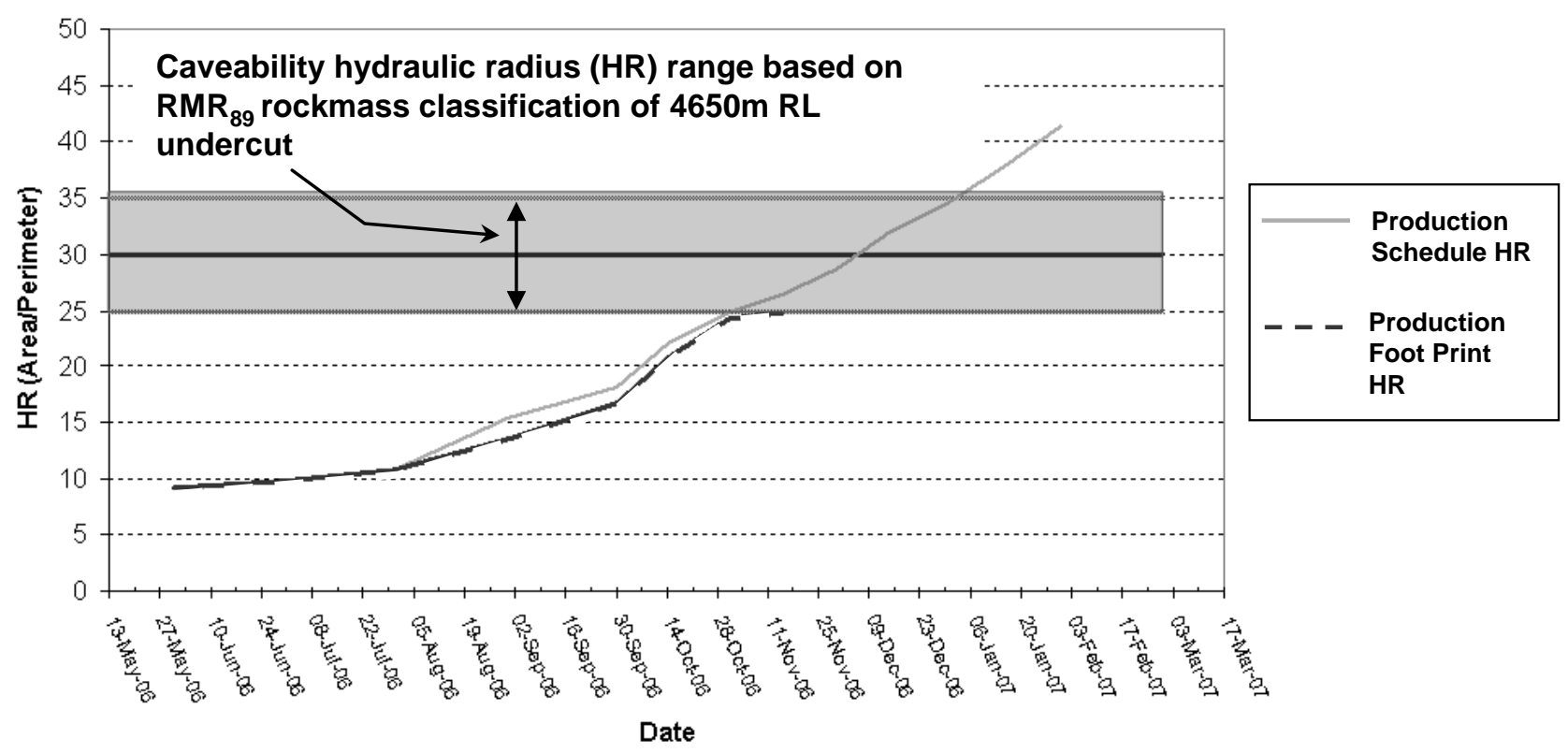

Figure 6 Undercut scheduled and approximated hydraulic radius (HR) versus time; transition to caving HR range is an estimate based on localised rock mass classification

Mapping the location of the caving front and advance rate was reliant on the microseismic data in combination with the DHSE data. This combined data interpretation was applied for the period from undercut initiation through to the DHSE displacement limits being reached or communication loss to the headframes of the extensometers. The microseismic data correlated well spatially with early undercut extraction to 30 October 2006 as event rate increased (Figure 7).

On a month by month frequency the caving front position was estimated for Phase 1 monitoring through to the $4850 \mathrm{~m} \mathrm{RL}$. Above this extensometer data at the cave apex was not available. The upper surface of the seismogenic zone for a 30 day subset of data was compared to DHSE data at the end of that period. A point was estimated along the extensometer column below which all functioning anchors have a constant displacement rate (Figure 4). This point was determined to delineate the top of the zone below which cave material was mobile. Using this information the cave propagation rate was calculated (Figure 8). For Phase 1 monitoring the cave propagation rate was calculated to average $0.64 \mathrm{~m} /$ day at 30 July.

\subsection{Determination of air gap potential}

The DHSE displacement rate data combined with microseismic event frequency indicated that these systems may be utilised to assess the reduction of the void between the cave back and the muck pile as yielded rock filled this volume, therefore eliminating air gap during times of low or no draw from the SLC. The interpretation of this set of relationships was repeated four times through the cave propagation period from 4675 to $4860 \mathrm{~m}$ RL. Although full confidence may not be placed on this interpretation, the drop of microseismic event frequency and the reduction of DHSE anchor displacement rate to zero enabled a judgement that only a minimal air gap at the DHSE intersections of the cave column existed. This air gap must have been minimal since the lag between not drawing from the SLC and the reduction in seismic activity and DHSE deformation was approximately four to five days. In this period the air gap to becomes choked with material falling from the cave backs. However, this could not be verified with open borehole dipping methods. Figure 9 displays the recorded DHSE and microseismic data through a period of no draw due to production shutdown. 

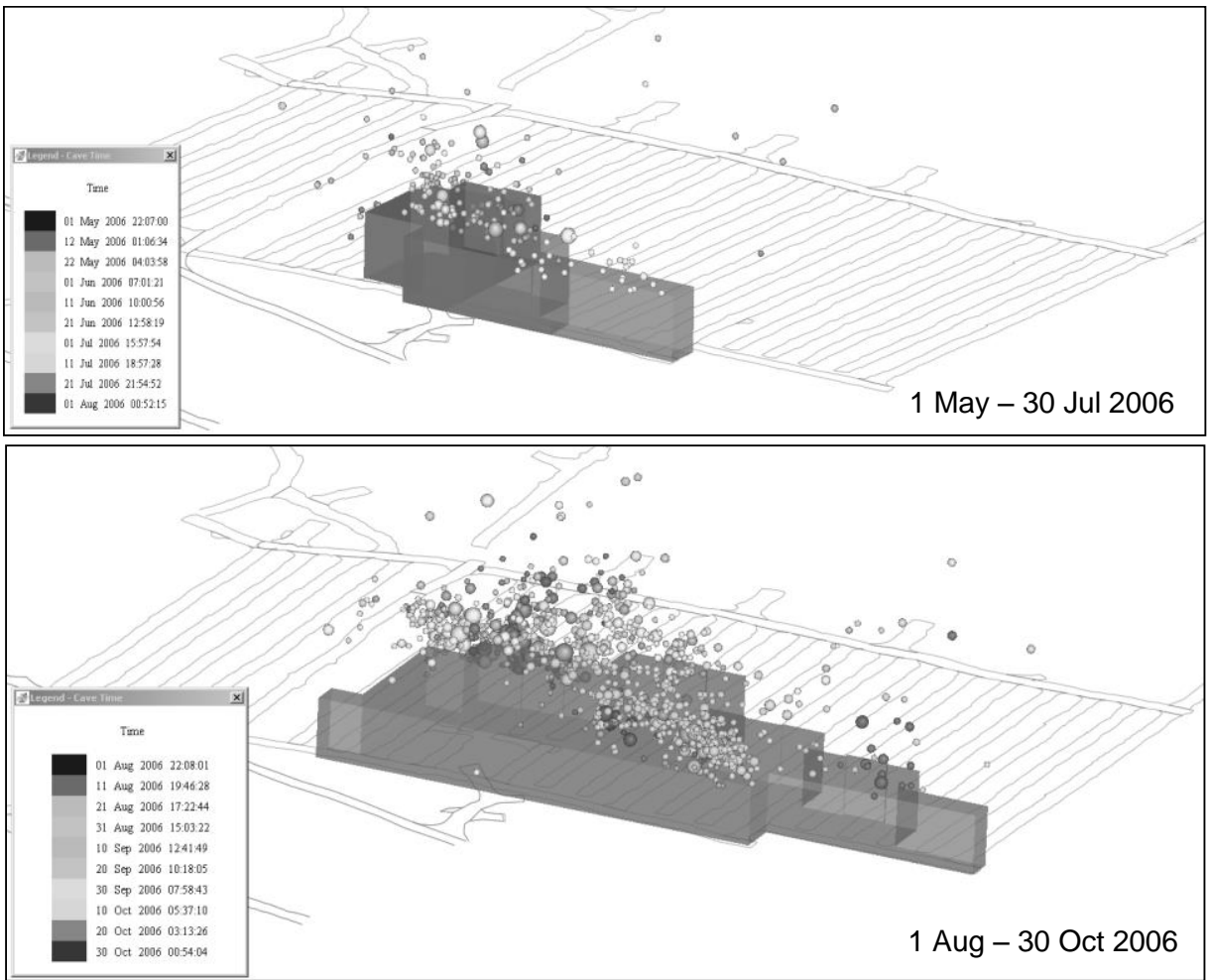

Figure 7 Microseismic response to early undercut extraction

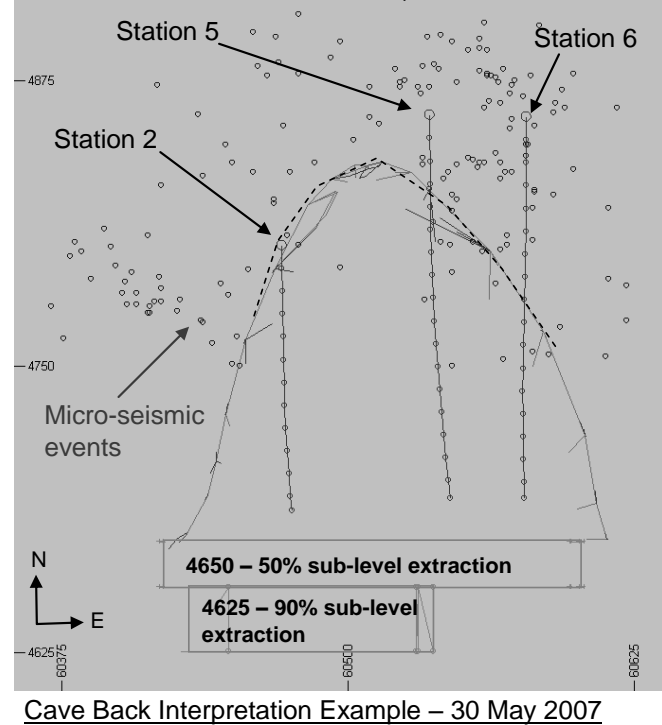

A $20 \mathrm{~m}$ wide slice of 30 day micro-seismic data set is correlated against extensometer anchor displacement. 'Cave back' position is estimated between lower boundary of seismogenic zone and above anchors of constant displacement rate at the end of the period.

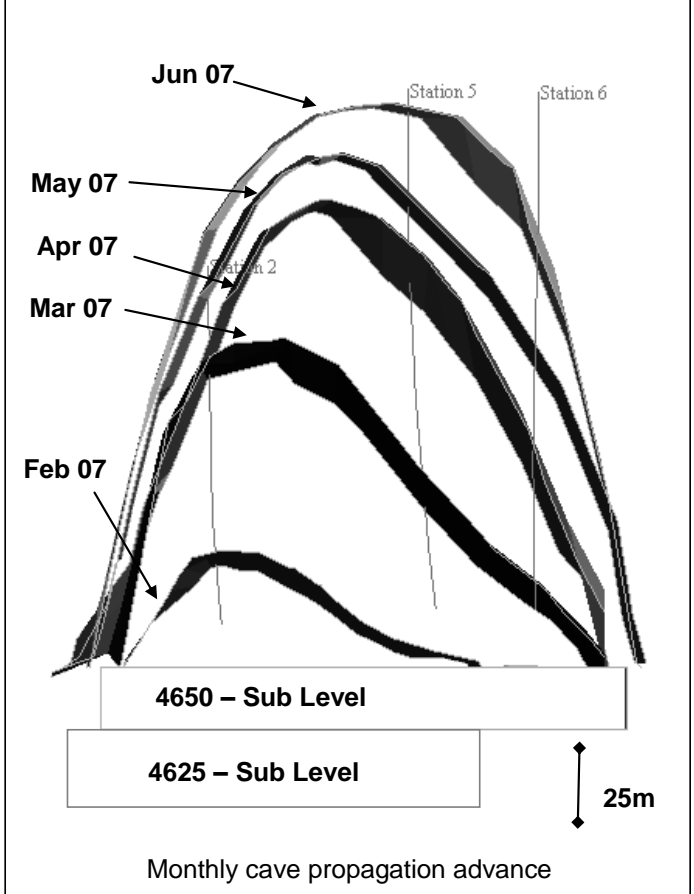

Figure 8 Monthly interpretations of cave advance using microseismic and DHSE data 


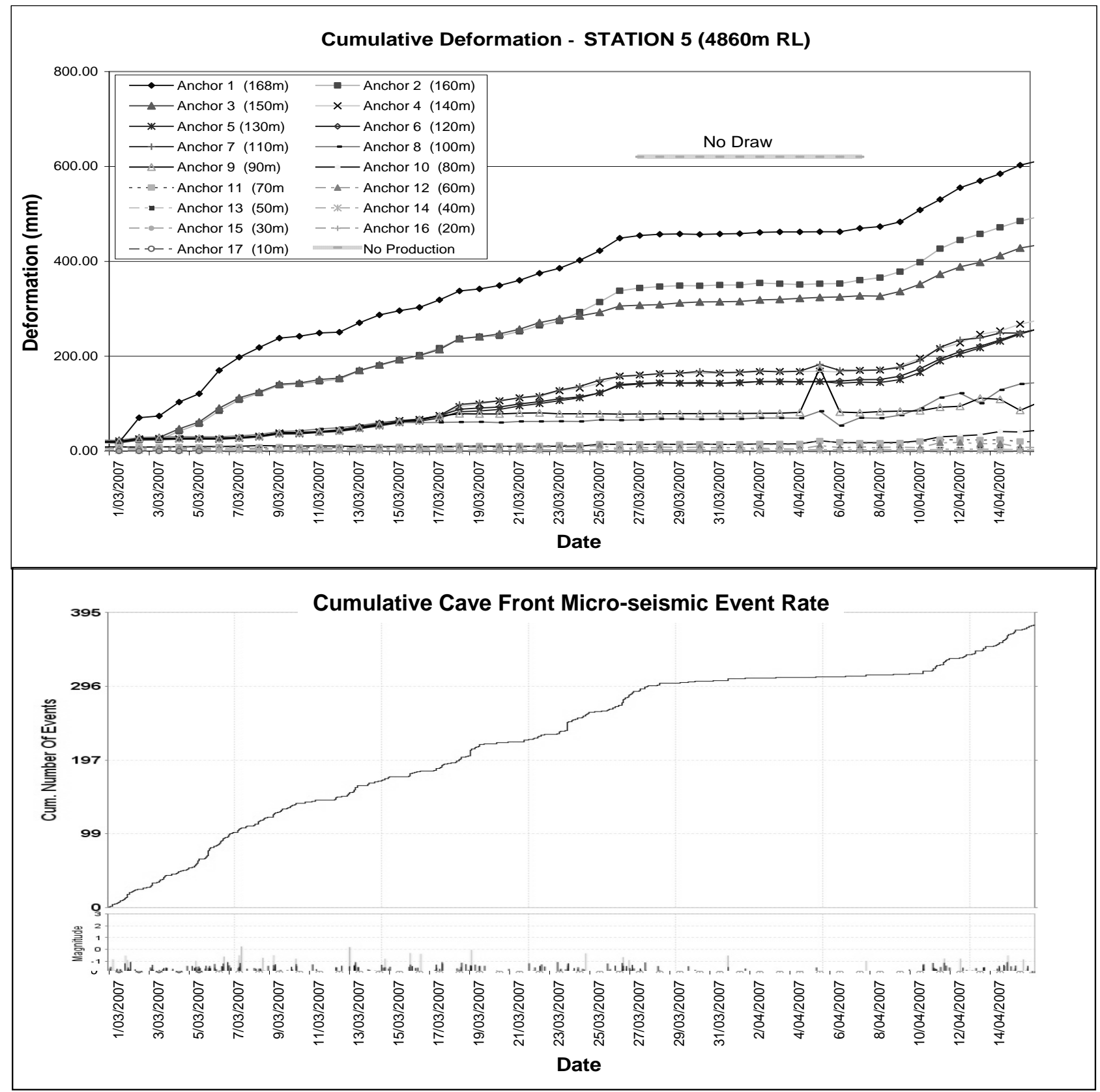

Figure 9 Comparison of DHSE displacement rate and microseismic event frequency during the same time interval. Displayed is a period of no production draw from the SLC where both rates reduce around the same period and then increase as draw recommences

\section{Conclusions}

Instrumentation of the Telfer Deeps SLC provided a framework for interpretation that assists cave management. The benchmarking of other cave mine experience assisted in the establishment of ground monitoring systems before the undercut extraction commenced. The availability of existing excavations immediately above the undercut footprint enabled drilling and installation of both microseismic and DHSE instruments along with visual observations. Both quantitative systems proved to be reliable enough to monitor the initial cave propagation through Phase 1 of the cave column.

The interpretation of the available data required judgement and knowledge of the local conditions. However, the location of the cave backs and the extents of caving, as well as the rate of cave propagation could be quantified to a reasonable degree of accuracy, enabling the mine to manage the hazards associated with 
caving. The lack of open whole dipping opportunity for air gap determination was replaced with interpretation and judgement of the microseismic and DHSE response.

\section{Acknowledgements}

The authors would like to acknowledge Newcrest Mining Limited for allowing publication of this paper. The Underground Geotechnical Department is acknowledged for the design and development of the monitoring systems. The group wide geotechnical team for support and peer review of system design and data interpretation.

\section{References}

Glazer, S. (2005) Telfer Evaluation of the Phase 1 Seismic System Design at Telfer Gold Mine, Internal unpublished document.

Groocock, D. (2006) Telfer Cave Propagation Zone Sub Domaining, Internal unpublished document.

Integrated Seismic Systems International (ISSI) (2007) JDI - Seismic Visualization and Analysis Software Package, Version 4.7.

Laubscher, D.H. (1994) Cave Mining - State of the Art, Journal South African Institute of Mining and Metallurgy, Vol. 94(8).

Maxlow, J. (2007) Newcrest Mining Limited, Telfer Geology, Reference Manual, TS-REP-DEV-0060, Internal unpublished document.

Pfitzner, M.J. (2003) Monitoring a blind sublevel cave - A case study of an integrated approach at Newcrest Mining's Ridgeway Gold Mine, in Proceedings First Australasian Ground Control in Mining Conference, Ground Control in Mining; Technology and Practice, B.K. Hebbelwhite (ed), University of New South Wales, Australia, pp. 113-122.

SRK Consulting (2002) Report for Newcrest Mining Limited, Geotechnical Feasibility - Telfer Deeps, SRK Project Code NN202, Telfer Document No. TP-REP-20-GO-0094, Internal unpublished document.

Wienand, R. (2006) Telfer Geotechnical Instrumentation Programme Budget, TS-STR-GEO0005, Internal unpublished document. 
